C H A P T E R

\title{
Challenging Social Inequalities in Health
}

\author{
Michael Murray and David F. Marks
}

Half the world-nearly three billion people-live on less than two dollars a day. ... Nearly a billion people entered the 21st century unable to read a book or sign their names. . . Less than one percent of what the world spent every year on weapons was needed to put every child into school by the year 2000 and yet it didn't happen.

-Shah, 2006

$\Gamma$ hroughout the world millions of people continue to live in poverty. This is not just in the developing world, the Global South, but also in the developed world. Despite advances in overall wealth, substantial poverty still exists in many Western societies. In the United Kingdom, the proportion of individuals living in poverty increased from $15 \%$ in 1981 to $22 \%$ in 2002 to 2003 , representing 12.4 million people (Paxton \& Dixon, 2004). Other indicators of social inequality in the United Kingdom include the following:

- The richest people have increased their share of total income. The richest $1 \%$ increased their share of income from $6 \%$ in 1980 to $13 \%$ in 1999.

- The concentration of wealth continues to increase. The percentage of wealth held by the richest $10 \%$ of the population increased from $47 \%$ in 1990 to $56 \%$ in 2001.

In the United States, evidence shows a continuing increase in poverty. Using a more restrictive definition of poverty, the U.S. Census Bureau estimated that the proportion of Americans living in poverty increased from $11.3 \%$ in 2000 to $12.5 \%$ in 2003. In households of single mothers, poverty increased from $25.4 \%$ in 2000 to $28 \%$ in 2003 (DeNavas-Walt, Proctor, \& Mills, 2004). According to figures from the Congressional Budget Office (2006), the inequality in income between the richest and poorest households in the U.S. continues to rise with the share of after-tax income going to the wealthiest one percent rising from 12.2 to $14 \%$ between 2003 and 2004 , the largest one-year increase in 15 years. 


\section{POVERTY AND HEALTH}

\section{Socioeconomic Status}

Health and wealth are clearly connected. Substantial research evidence from dozens of countries links socioeconomic status (SES) with health. These studies have consistently shown that the life expectancy of those in the lower social classes is lower than those in the higher social classes. Evidence also indicates that there is a social gradient in morbidity and mortality such that the social group one step down the social ladder is unhealthier than those at the top and so on. This persistent gradient is often referred to as the bealth gradient. When mortality is the measure, a more apposite term would be the "mortality gradient" or "death gradient." Death gradients have been observed in all human societies in both rich and developed countries (Kunst \& Mackenbach, 1994) and in poor and developing countries (Marks, 2004).

The connection between SES and health occurs in the context of the family. SES is commonly evaluated in light of the occupation, education, or income level of the heads of each household. In the United Kingdom, for example, the head of a household consisting of a family is assumed to be the male parent (father). Yet the gradients we describe here are not restricted to fathers. They apply to all members of a family, and the effects of SES on health are replicated across gender and age. In the data shown in Figure 19.1, we can observe the impact of household economic status on the mortality rates among infants living in those households. Therefore, we can be quite certain that SES has a comprehensive impact on the health of all members of a household, both young and old.

Arguably, the impact may well be higher among mothers, daughters, and infants than on fathers and sons because of cultural assumptions favoring males to females in feeding habits, education, and employment.
The death gradient such as that shown in Figure 19.1 shows a steady increase in infant mortality as SES decreases.

Similar gradients exist in all societies including the United States, the United Kingdom, and all other industrialized and developing countries. If the gradient were stepped, or flat at one end of the range and steep at the other, it could be inferred that the causative mechanism(s) had a threshold value before any of the ill effects could appear. However, there is no evidence of any such thresholds. For most data, the gradient is a continuous one.

\section{Black Report}

In 1977, the United Kingdom government established a working group to investigate the relationship between social position and health. The subsequent Black Report (Townsend \& Davidson, 1982)—named after Sir Douglas Black, the working group chair-summarized the evidence on the relationship between occupation and health. It showed that those classified as unskilled manual workers (Social class V) consistently had poorer health status compared with those classified as professionals (Social class I).

The report clearly documented the link between social position and health and detailed four possible explanations:

- Artifact explanations: The relationships between health and social position are an artifact of the method of measurement.

- Natural and social selection: The social gradient in health is due to those who are already unhealthy falling whereas those who are healthy rise.

- Materialist and structuralist explanations: This explanation emphasizes the important role of economic and associated sociostructural factors.

- Cultural and behavioral explanations: These explanations "often focus on the individual 


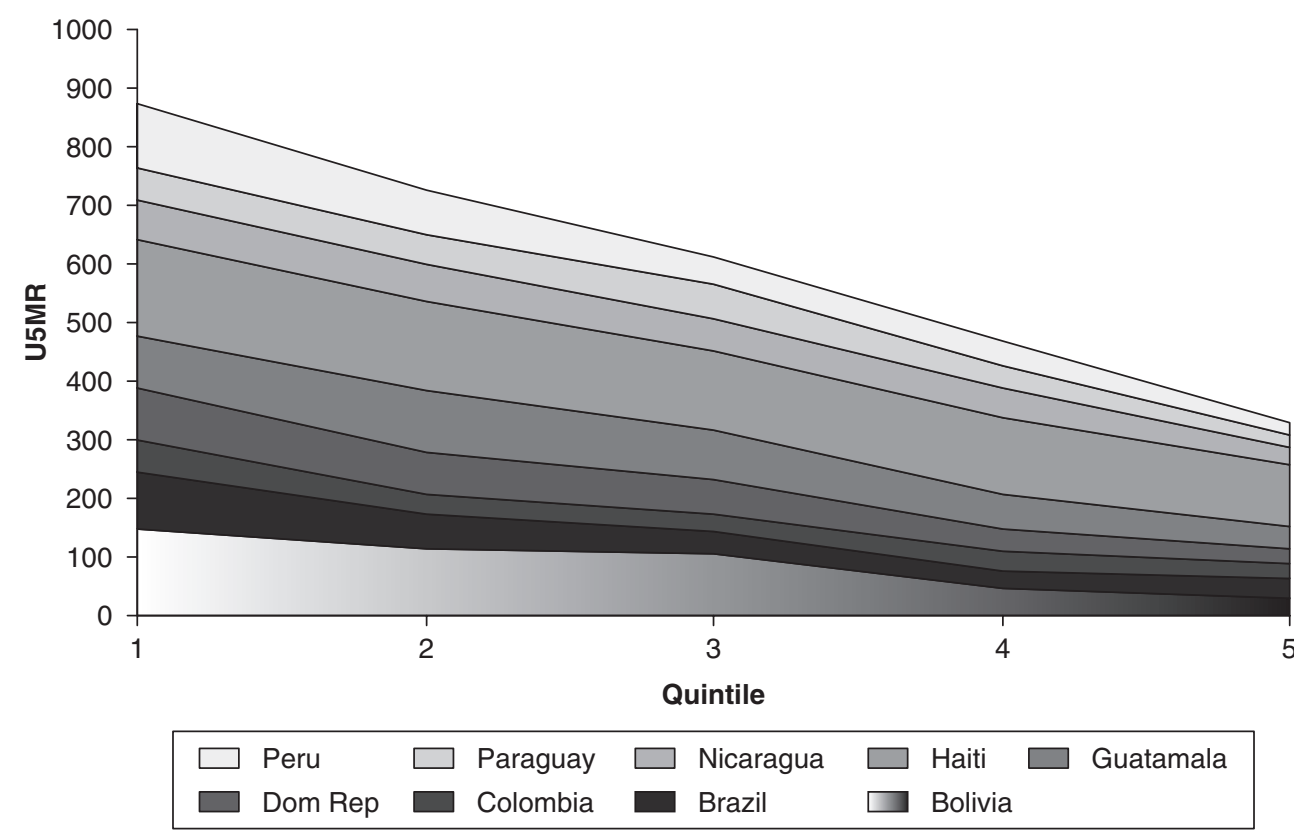

Figure 19.1 Under 5 Mortality in Latin America and the Caribbean According to Poverty Level Quintile From Poorest to Richest (from left to right)

as the unit of analysis emphasizing unthinking, reckless or irresponsible behaviors or incautious lifestyle as the moving determinant" (Townsend and Davidson, 1982, p. 23).

Although accepting that each explanation may contribute something, the report emphasized the importance of the materialist explanations and developed a range of policy options that could address the inequalities.

\section{Ecological Approach}

The relationship between social position and health can also be considered from an ecological perspective or systems theory approach. Bronfenbrenner's (1979) ecological approach conceptualized developmental influences in terms of four nested systems:

- Microsystems: Families, schools, neighborhoods

- Mesosystems: Peer groups
- Exosystems: Parental support systems, parental workplaces

- Macrosystems: Political philosophy, social policy

These systems form a nested set, like a set of Russian dolls, microsystems within mesosystems, mesosystems within exosystems, and exosystems within macrosystems. In Table 19.1, we list some of the characteristics of low SES using Bronfenbrenner's systems approach. The table shows how many different disadvantages there can be across all four systems of the social, physical, and economic environment. In addition to these factors, we can add the low levels of actual and perceived injustice that many people with low SES experience and feel in their everyday lives.

Any explanation of the SES-health gradient needs to consider psychosocial systems that structure inequalities across a broad range of life opportunities and outcomes-health, social and educational. As illustrated in Table 19.1, 
Table 19.1 Behaviors and Experiences Associated With Low SES

Microsystems_families, schools, neighborhoods

- Low weight births

- Family instability

- Poor diet/nutrition

- Parental smoking and drinking

- Overcrowding

- Poor schools and educational outcomes

- Poor neighborhoods

Mesosystems-peer groups

- Bullying, gangs, and violence

- Smoking and drinking

- Drugs

- Unprotected sex

Exosystems-parental support systems, parental workplaces

- Low personal control

- Less social support

- Unemployment or unstable employment

- High stress levels

- Low self-esteem

- Poorer physical and mental health

Macrosystems-political philosophy, social policy

- Poverty

- Poor housing

- Environmental pollution

- Unemployment or unstable employment

- Occupational hazards

- Poorer access to health services

- Inadequate social services

in comparison with someone at the high end of the SES scale, the profile of a low SES person is one of multiple disadvantages. The disadvantages of low SES accumulate across all four ecosystems and throughout the family.

This kind of accumulation and clustering of adverse physical, material, social and psychological effects helps explain the health gradient (Davey-Smith, Blane, \& Bartley, 1994). Although each factor alone can be expected to produce a relatively modest impact on mortality, the combination and interaction of many kinds of ecosystem disadvantage are likely to be sufficiently large to generate the observed gradient.

\section{SOCIAL INEQUALITIES AND HEALTH}

The distribution as well as the level of wealth and poverty in society are important. Much research has focused on the relationship between the extent of social inequality in a particular society and the extent of ill health. This research was particularly developed by Wilkinson (1996), who argued that overall health was poorer in the more unequal societies. Thus, health was affected not just by absolute deprivation but also by relative deprivation. This research has attracted substantial debate, and it would seem that the 
relationship is not as straightforward as was initially conjectured. Rather, there is much more to social inequality than inequality of income. We need also to consider inequality in access to resources and education and differentials in power between groups in society.

\section{Scientific Explanations}

Contemporary research into explanations for social inequalities in health has been reviewed by Marinko, Shi, Starfield, and Wulu (2003). Their classification extends the four-fold explanation developed in the Black Report and is summarized in Table 19.2.

The psychosocial explanations are considered at both the more individual (micro) and the more social (macro) level. At the micro level, some argue that "cognitive processes of comparison," in particular perceived relative deprivation, contribute to heightened levels of stress and subsequent ill-health. At the macro-level, psychosocial explanations focus on impairment of social bonds and limited civic participation, so-called social capital (see later), that flows from income inequality. These explanations are particularly favored by Wilkinson (1996) to explain the social gradient in health.

Material explanations focus on the importance of income and living conditions (see Macleod \& Davey-Smith, 2003). At the micro-level, some argue that in a more unequal society, those worse off have fewer economic resources, which leads to increased vulnerability to various health threats. At the macro level, high-income inequality contributes to less investment in the social and physical environment. Those who favor the material explanations argue that the psychosocial explanations ignore the broad political context within which social and health inequalities are nested.

There are also the artifact and selection explanations of the social inequalities in health. Although these initially attracted

Table 19.2 Explanations for the Relationship Between Income Inequality and Health

\begin{tabular}{ll}
\hline Explanation & Synopsis of the Argument \\
\hline $\begin{array}{l}\text { Psychosocial (micro) } \\
\text { Social status }\end{array}$ & $\begin{array}{l}\text { Income inequality results in "invidious processes of social comparison" } \\
\text { that enforce social hierarchies causing chronic stress leading to poorer } \\
\text { health outcomes for those at the bottom. }\end{array}$ \\
$\begin{array}{l}\text { Psychosocial (macro) } \\
\text { Social cohesion }\end{array}$ & $\begin{array}{l}\text { Income inequality erodes social bonds that allow people to work } \\
\text { together, decreases social resources, and results in low trust and civic } \\
\text { participation, greater crime, and other unhealthy conditions. }\end{array}$ \\
$\begin{array}{l}\text { Material (micro) } \\
\text { Individual income }\end{array}$ & $\begin{array}{l}\text { Income inequality means fewer economic resources among the poorest, } \\
\text { resulting in lessened ability to avoid risks, treat injury or disease, or } \\
\text { prevent illness. }\end{array}$ \\
$\begin{array}{l}\text { Material (macro) } \\
\text { Social disinvestment }\end{array}$ & $\begin{array}{l}\text { Income inequality results in less investment in social and environmental } \\
\text { conditions (safe housing, good schools, etc.) necessary for promoting } \\
\text { health among the poorest. }\end{array}$ \\
Statistical artifact & $\begin{array}{l}\text { The poorest in any society are usually the sickest. A society with high } \\
\text { levels of income inequality has high numbers of poor and consequently } \\
\text { will have more people who are sick. }\end{array}$ \\
People are not sick because they are poor. Rather, poor health lowers \\
one's income and limits one's earning potential.
\end{tabular}

SOURCE: Based on Marinko et al. (2003). 
attention, these arguments have less support today (Bartley Blane, \& Davey-Smith, 1998).

\section{Lay Explanations}

Recently, there has been increasing interest in what ordinary people have to say about social inequalities in health. This literature connects with the broader literature on popular health beliefs. In an early qualitative study of a sample of women in England, Calnan (1987) found that working-class women were reluctant to accept that they were less healthy than middle-class people. Those who did accept that wealthy people had better health attributed it to differential access to health care. Conversely, professional women were more likely to accept the existence of a health gradient and attributed the poorer health of working-class people to low job satisfaction, low wages, poor diet and the hazards of the working environment.

Chamberlain (1997) reviewed evidence from qualitative research concerning how people from upper and lower SES positions understand health and illness. These studies interviewed small groups of middle-class and working-class women and men classified on the basis of their occupations. Several differences are evident between these two groups. Working-class people tend to use more physicalistic terminology in their accounts of health and illness whereas middle-class people are more mentalistic and person-centered (Blair, 1993). Contact and communication with professionals can be affected by their class relationship with patients so, not surprisingly, surgeons and doctors are often perceived as "upper" class by working-class patients, whereas nurses are seen as more "down to earth."

Lay explanations about social inequalities in health are apparent from an early age. A study in Scotland (Backett-Milburn, Cunningham-Burley, \& Davis, 2003) found that children identified social relationships and social life as important as material concerns in explaining health inequalities. This indicated that their direct experiences of relationships and unfairness were important to help them make sense of health inequalities. Further studies are needed to explore the relationship between social positioning and health experience.

\section{Power, Politics, and Health Inequities}

Much of the research on social inequalities in health has focused on differences in income or wealth. As such, it has ignored issues of power and politics. A more inclusive approach has been developed by Hofrichter (2003), who considers inequalities in terms of class, gender, and race. These three social groupings are linked by issues of social and material exploitation. This approach enables the development of a more expansive approach to explaining health inequities not only in terms of income inequality and poverty but also in terms of institutional racism, gender discrimination, corporate globalization, degradation of the environment, destruction of the public sector, dangerous workplace conditions, and neighborhood characteristics.

An important factor in explaining these processes is the weakening of working-class power and the strengthening of capital during the past generation. Greater workingclass power and political participation is associated with improved community health (Muntaner et al., 2002). Examples of the negative impact of increased corporate power itemized by Hofrichter (2003) include the following:

Economic disinvestment in poor communities, extensive layoffs, mass firings and restructuring, gentrification, targeting of industrial and toxic waste facilities in communities of color, elimination of protective regulatory structures, profiteering by drug 
companies seeking to maintain control of patents, financial speculation, use of dangerous technologies, restricting competition, shifting the tax burden to the less fortunate, tax subsidies to wealthy corporations, and failure to improve living conditions for farm workers. (p. 23)

These factors in turn threaten already weakened communities leading to further stress and ill health.

Coburn (2004) developed an integrative, class/welfare model, in which issues of income inequality and social cohesion are nested within a broader causal chain. This model argues that during the past 20 years, the power of business has increased but that of the working class has declined. This has been achieved through the introduction of neoliberal policies by the ruling class that have increased income inequality, led to poverty, and reduced access to services. In those countries with more social democratic rather than neoliberal governments, the power of capital has been resisted and the impact on health has been less. Coburn (2004) argues that this benefit to health has been achieved through both material and psychosocial advantages.

\section{HEALTH AND PLACE}

Although the evidence linking ill health and poverty is clearly established, evidence also suggests regional or area variations. This has given rise to a growing program of research on health and place that has explored how major structural changes, such as those itemized earlier, lead to ill health. Features of unhealthy environments include threats to safety and to the creation of social ties (Repetti, Seeman, \& Taylor, 1997). Conversely, healthy societies provide safety, opportunities for social integration, and the ability to predict and control our social world. Unhealthy environments are associated with chronic stress.
The social characteristics of a person's local neighborhood can act as an independent predictor of health. A study of four localities in the United States found that residents of disadvantaged neighborhoods had a higher risk of disease than did residents of advantaged neighborhoods, even after controlling for personal income, education, and occupation (Diez Roux et al., 2001). In an accompanying editorial, Marmot (2001) states,

Walk the slums of Dhaka, in Bangladesh, or Accra, in Ghana, and it is not difficult to see how the urban environment of poor countries could be responsible for bad health. Walk north from Manhattan's museum district to Harlem or east from London's financial district to its old East End, and you will be struck by the contrast between rich and poor, existing cheek by jowl. It is less immediately obvious why there should be health differences between rich and poor areas of the same city. It is even less obvious, from casual inspection of the physical environment, why life expectancy for young black men in Harlem should be less than in Bangladesh.

The findings of Diez Roux et al. (2001) suggest an important target for intervention: the neighborhood. This finding is exactly what would be expected from a community perspective.

Three theoretical approaches to the study of health and place have been identified (Curtis \& Jones, 1998):

- Hazard exposure: Physical and biological risk factors are spatially distributed. This approach posits a direct pathway between hazard exposure and health risk.

- Social relationships: Space and place shape the character of social relationships and, in turn, psychosocial and behavioral risk factors.

- Sense of place and subjective meanings: This approach considers the shared social meanings people have of their communities. 
The first explanation includes all aspects of the physical environment and includes environmental and occupational hazards, threats to personal safety, and the like. The second explanation connects with the growing literature on social capital, whereas the third is connected with the literature on community identity and community narratives.

\section{Social Capital}

Social capital is increasingly used as an aid to explaining social variations in health. The concept has been especially promoted by Robert Putnam, who used it to characterize civic life in Italy (Putnam, Leonardi, \& Nanette, 1993). He argued that certain communities had higher degrees of civic engagement, levels of interpersonal trust, and norms of reciprocity. Together, these characteristics contributed to a region's degree of social capital. Putnam (2000) subsequently explored the extent of social capital in the United States and argued that during the past generation, there has been a steady decline in participation in social organizations and thus a steady decline in social capital.

A series of studies have investigated social variations in social capital and its connection with health. Kawachi et al. (1994) found states with a low degree of income inequality also had low social capital as measured by group membership and social trust. Further, those states with high rates of social mistrust and low rates of membership of voluntary organizations had higher mortality rates.

A qualitative study by Campbell, Wood, and Kelly (1999) compared the sense of community engagement in two communities near London. They reported evidence that two aspects of social capital (trust and civic engagement/perceived citizen power) were higher in the "high health" community but two aspects (local identity and local community facilities) were higher in the "low health community." Campbell and Wood suggested that certain aspects of social capital, in particular perceived trust and civic engagement, are more health enhancing than others are. Whereas Putnam et al. (1993) emphasized the importance of voluntary associations, Campbell and Wood found that these were rare in both communities. However, whereas the "low health" community made almost no reference to communitylevel networks in their community, these phenomena (e.g., residents' associations) were important in the "high health" community.

An important distinction that Putnam (2000) makes is that between bridging and bonding social capital. The latter refers to inward-looking social ties that bond the community together. Bridging social capital refers to links with diverse groups and provides an opportunity for community members to access power and resources outside their community. Both forms of social capital are essential in building healthy communities (Campbell \& Murray, 2004).

Social capital has been widely criticized as an explanatory concept (e.g., Lynch, Due, Muntaner, \& Davey-Smith, 2000). There is confusion about what exactly the term implies, there are debates about ways of measuring it, and there is ignorance of the broader political context. An interest in social relations does not preclude acceptance of the importance of political and material factors; however, Baum $(1999,2000)$ emphasizes caution in the use of the concept because "there are dangers that the promotion of social capital may be seen as a substitute for economic investment in poor communities particularly by those governments who wish to reduce government spending."

\section{Community Identity}

An alternative to the rather behaviorist assumptions underlying much of the work on social capital is to consider the character of the community sense of meaning. The most comprehensive investigation of these 
processes is the work by Popay and colleagues (2003). They conducted a detailed ethnographic study of four neighborhoods in North West England. Popay et al. found that residents of the more disadvantaged neighborhoods identified place as the major explanation for health inequalities, whereas those in relatively advantaged areas preferred individualistic explanations. However, the residents often suggested a complex interaction of macro-structural, place, and lifestyle factors. For example, the residents of the more disadvantaged areas described how macro-structural factors interacted with place-based factors shaping particular lifestyle patterns. The mediating factor linking these factors was often seen as stress.

The way the residents described their communities was categorized into three normative guidelines:

1. Relationships: This guideline emphasized the importance of supportive social relationships with neighbors, trust and respect between people, and respect for property.

2. Physical dimensions: This guideline referred to aspects of safety, appropriateness, convenience, and cleanliness.

3. Ontological identity: This guideline is concerned with the relationship between one's sense of identity and place.

These guidelines helped distinguish between "good" and "bad" neighborhoods. It was not simply the material disadvantage of the neighborhood but, rather, the community dynamics and the extent to which the residents could identify with it. The residents of more disadvantaged areas reported more problems with their neighbors and less safety. These residents were also less likely to identify with their neighborhood. An important component of this research was the emphasis on the importance of community narratives (Popay, 2000; Williams, 2003). Attention to these narratives enabled the researcher to understand the lived experience of people's lives, of the connections between social and political change and everyday life.

\section{REDUCING INEQUALITIES}

Reducing these social inequalities requires adopting a thoroughly multilayered approach. Whitehead (1995) identified four different levels for tackling health inequalities:

1. Strengthening individuals

2. Strengthening communities

3. Improving access to essential facilities and services

4. Encouraging macroeconomic and cultural change

These four levels correspond to the four layers of influence in Whitehead's “onion model" of the determinants of health. Extra microsystem and mesosystem levels, as in Bronfenbrenner's model, could be added to this list.

Interventions aimed at tackling inequalities at an individual level have shown mixed results. There are four possible reasons. First, people living and working in disadvantaged circumstances have fewer resources (time, space, money) with which to manage the process of change. Second, health-threatening behaviors such as smoking tend to increase in difficult or stressful circumstances because they provide a means of coping (Graham, 1993). Third, there may have been a lack of sensitivity to the difficult circumstances in which people work and live that constrain the competence to change. Fourth, there has been a tendency to blame the victim. For example, cancer sufferers may be blamed for the disease if they are smokers on the grounds that they are responsible for the habit that caused the disease.

Overall, efforts directed at the individual level have been inconclusive and small scale. 
Because many health determinants are beyond the control of the individual, psychological interventions aimed at individuals are likely to have limited impact on public health problems when considered on a wider scale. This suggests a need for psychologists to work beyond the individual level, with families, communities, work sites, and community groups.

Efforts to tackle inequalities typically have two shortcomings (see Benzeval, Judge, \& Whitehead, 1995):

1. Excessive attention is given to the health experiences of white males of working age compared with women, older people, people with disabilities, and minority ethnic groups. More attention needs to be given to the health concerns of these under-served groups.

2. The policy areas dealt with in detailhousing, income maintenance, smoking, and access to health care-are insufficiently comprehensive as an agenda for tackling inequalities.

Tackling health inequalities at the level of services to individuals is insufficient. The correction of inequalities in health demands "a wide-ranging and radical reshaping of economic and social policies" (Benzeval et al., 1995 , p. 40). In other words, policy change at Levels 3 and 4 is required to bring about economic and cultural change.

\section{SOCIAL JUSTICE AND HEALTH}

\section{Social Justice}

Critics of the research into social inequalities in health often charge that social inequalities are both an inevitable part of life and also are necessary for social progress. An alternative perspective is to consider not simply inequalities per se but inequities in health. Health inequalities can be considered as inequities when they are avoidable, unnecessary, and unfair (Dahlgren \& Whitehead, 1991). The issue of fairness leads us to consider the issue of social justice and health.

A useful starting point is the theory of "justice as fairness" developed by the moral philosopher John Rawls (1999). He identified certain underlying principles of a just society:

- Ensure people equal basic liberties including guaranteeing the right of political participation

- Provide a robust form of equal opportunity

- Limit inequalities to those that benefit the least advantaged

When these principles are met, citizens can be confident that they are respected by others and can acquire a sense of self-worth.

Adhering to these principles could begin to address the basic social inequalities in health. Daniels, Kennedy, \& Kawachi (2000) detail a series of implications for social organization that flow from the acceptance of these principles. First, ensuring people have equal basic liberties implies that everyone has an equal right to fully participate in politics. This will in turn contribute to improvements in health because, according to social capital theory, political participation is an important social determinant of health.

Second, providing active measures to promote equal opportunities implies the introduction of measures to reduce socioeconomic inequalities and other social obstacles to equal opportunities. Such measures would include comprehensive child-care and childhood interventions to combat any disadvantages of family background. They would also include comprehensive health care for all including support services for those with disabilities.

Finally, a just society would allow only those inequalities in income and wealth that would benefit the least advantaged. This requires direct challenge to the contemporary neoliberal philosophy that promotes the maximization of profit and increasing the extent of social inequality. 


\section{Health and Social Justice}

To reduce the inequalities in health, a research and advocacy agenda on issues of social and economic justice needs to be developed (cf. Bullock \& Lott, 2001). Such an agenda would be concerned not just with describing the impact of poverty and inequality on health and well-being but also with advocating for social and economic justice. It would include challenging the victim-blaming ideology that is often adopted in psychological approaches to the study of health and illness. It would also include defining health research as a resource for social change (Murray \& Campbell, 2003; Murray \& Poland, 2006). This would involve a variety of strategies and lead to a more politically engaged approach such as the one championed by Martin-Baro (1994), who challenged psychologists and social scientists to adopt a "preferential option for the poor."

Three approaches have been suggested by Fine and Barreras (2001):

1. Public policy: Documenting the impact of regressive social policies and agitating against such policies

2. Popular education: Challenging popular victim-blaming beliefs (common-sense) about the causes of ill-health

3. Community organizing: Working with marginalized communities and agitating for social change

The success of such a strategy requires building alliances with social groups most negatively affected by social inequalities. As Martin-Baro (1994) stressed, "The concern of the social scientist should not be so much to explain the world as to transform it” (p. 19).

\section{FUTURE DIRECTIONS}

Research on social inequalities in health needs to be clearly connected to exploring various strategies to reduce such inequalities. These can range from macro-level strategies to micro-level strategies. Of primary significance is the SES of the family considered as a social unit. The effects of SES on health are transmitted through families, communities, and regions. SES is not simply an individuallevel measure but a measure that applies to the entire family. More conceptual and theoretical effort should be allocated to the study of the mechanisms by which SES effects are transmitted across the whole family structure.

At the micro-level is a need to explore measures that can support healthy human development, especially in the early years. Studies of the health experiences of people from different socioeconomic backgrounds are particularly important to our understanding of the psychological mechanisms underlying health variations. Further research to explore the relationship between social positioning and health experience needs to connect with strategies for social and health professionals to engage with marginalized and disadvantaged sections of society.

At the meso-level is the need to intervene at the level of the group to explore ways of working in particular with disadvantaged young people who often feel isolated and rejected by mainstream society. In such a situation, they are more prone to engage in self-injurious practices.

At the exo-level is the need to evaluate various means of support especially for disadvantaged families and communities. Kim, Millen, Irwin, and Gershman (1999) called on researchers to adopt "a practice of 'pragmatic solidarity'... with and for the pooracknowledging primary accountability to poor communities and their needs." In doing so, the aim is to develop effective action "to resist the multiple forces that threaten the health and survival of poor people today" (p. 391).

At the macro-level is a need to explore how widespread political changes affect the health of communities. This involves participating in 
ongoing critique and challenge to unjust social policies in developed and developing nations. In Africa and in many parts of Asia and Latin America, the levels of poverty are horrendous. In a world of plenty, it is intolerable that such levels of poverty continue to exist. Sachs (2005) estimates that poverty could be eliminated within 20 years through concerted international action. However, eliminating it requires widespread political action. In 2002, world leaders pledged to work toward a target of $0.7 \%$ of their national income in international aid. On average, the world's richest countries provide just $0.33 \%$ of their gross national product in official development assistance (ODA). The United States provides just
$0.22 \%$. If developed nations increased their ODA to $0.54 \%$ by 2015 , they would contribute almost $\$ 200$ billion, which would begin to end the extreme poverty throughout the world. However, money alone is not sufficient when developing nations are crippled by massive debt loads and world trading patterns continue to benefit the wealthier nations. More radical changes are needed in political arrangements.

In general, social research needs to move from observation and explanation of social inequalities in health to more action-oriented research that can challenge this social injustice and instead to develop strategies that in their practice lead to a more just and healthy society.

\section{REFERENCES}

Backett-Milburn, K., Cunningham-Burley, S., \& Davis, J. (2003). Contrasting lives, contrasting views? Understandings of health inequalities in differing social circumstances. Social Science \&o Medicine, 57, 613-623.

Bartley, M., Blane, D., \& Davey-Smith, G. (1998). Introduction: Beyond the Black Report. Sociology of Health and Illness, 20, 563-577.

Baum, F. (1999). Social capital: Is it good for your health? Issues for a public health agenda. Journal of Epidemiology and Community Health, 53, 195-196.

Baum, F. (2000). Social capital, economic capital and power: Further issues for a public health agenda. Journal of Epidemiology and Community Health, 54, 409-410.

Benzeval, M., Judge, K., \& Whitehead, M. (Eds.). (1995). Tackling inequalities in bealth: An agenda for action. London: King's Fund.

Blair, A. (1993) Social class and the contextualization of illness experience. In A. Radley (Ed.), Worlds of illness: Biographical and cultural perspectives on bealth and disease (pp. 27-48). London: Routledge.

Bronfenbrenner, U. (1979). The ecology of human development: Experiments by nature and design. London: Harvard University Press.

Bullock, H. E., \& Lott, B. (2001). Building a research and advocacy agenda on issues of economic justice. Analyses of Social Issues and Public Policy, 1, 147-162.

Calnan, M. (1987). Health and illness: The lay perspective. London: Tavistock.

Campbell, C., \& Murray, M. (2004). Community health psychology: Promoting analysis and action for social change. Journal of Health Psychology, 9, 187-195.

Campbell, C., Wood, R., \& Kelly, M. (1999). Social capital and health. London: Health Education.

Chamberlain, K. (1997). Socioeconomic health differentials: From structure to experience. Journal of Health Psychology, 2(3), 399-411. 
Coburn, D. (2004). Beyond the income inequality hypothesis: Class, neo-liberalism, and health inequalities. Social Science \& Medicine, 58, 41-56.

Congressional Budget Office. (2006, December). Historical effective federal tax rates: 1979 to 2004. Washington, DC: Author. Retrieved from http://www .cbo.gov/ftpdocs/77xx/doc7718/EffectiveTaxRates.pdf

Curtis, S., \& Jones, I. R. (1998). Is there a place for geography in the analysis of health inequalities? Sociology of Health and Illness, 20, 645-672.

Dahlgren, G., \& Whitehead, M. (1991). Policies and strategies to promote social equality in health. Stockholm: Institute of Future Studies.

DeNavas-Walt, C., Proctor, B.D., \& Mills, R.J. (2004). Income, poverty, and health insurance coverage in the United States: 2003. U.S. Census Bureau, Current Population Reports, P60-226. Washington, DC: U.S. Government Printing Office.

Daniels, N., Kennedy, B., \& Kawachi, I. (2000). Justice is good for our health: How greater economic equality would promote public health. Boston Review, $25(1), 6-15$.

Davey-Smith, G., Blane, D., \& Bartley, M. (1994). Explanations for socioeconomic differentials in mortality. European Journal of Public Health, 4, 131-144.

Diez-Roux, A. V., Merkin, S. S., Arnett, D., Chambless, L., Massing, M., Nieto, F. J., et al. (2001). Neighborhood of residence and incidence of coronary heart disease. New England Journal of Medicine, 345, 99-106.

Fine, M., \& Barreras, R. (2001). To be of use. Analyses of Social Issues and Public Policy, 1, 175-182.

Graham, H. (1993). When life's a drag: Women, smoking and disadvantage. London: Her Majesty's Stationery Office.

Hofrichter, R. (2003). The politics of health inequities: Contested terrain. In R. Hofrichter (Ed.), Health and social justice: Politics, ideology, and inequity in the distribution of disease. San Francisco: Jossey-Bass.

Kawachi, I., Colditz, G. A., Ascherio, A., Rimm, E. B., Giovannucci, E., Stampfer, M. J., et al. (1994). Prospective study of phobic anxiety and risk of coronary heart disease in men. Circulation, 89, 1992-1997.

Kim, J. Y., Millen, J. V., Irwin, A., \& Gershman, J. (Eds.). (1999). Dying for growth: Global inequality and the health of the poor. Monroe, ME: Common Courage Press.

Kunst A. E., \& Mackenbach J. P. (1994). The size of mortality differences associated with educational level in 9 industrialised countries. American Journal of Public Health, 84, 932-937.

Lynch, J., Due, P., Muntaner, C., \& Davey-Smith, G. (2000). Social capital-Is it a good investment for public health? Journal of Epidemiology and Community Health, 54, 404-408.

Macleod, J., \& Davey-Smith, G. (2003). Psychosocial factors and public health: A suitable case for treatment? Journal of Epidemiology and Community Health, 57, 565-570.

Marinko, J. A., Shi, L., Starfield, B., \& Wulu, J. T. (2003). Income inequality and health: A critical review of the literature. Medical Care Research and Reviews, 60, 407-452.

Marks, D. F. (2004). Rights to health, freedom from illness: A life and death matter. In M. Murray (Ed.), Critical health psychology. London: Palgrave.

Marmot, M. (2001). Inequalities in health [Editorial]. New England Journal of Medicine, 345, 134-136. 
Martin-Baro, I. (1994). Writings for a liberation psychology (A. Aron \& S. Corne, Eds.). Cambridge, MA: Harvard University Press.

Muntaner, C., Lynch, J., Hillemeier, M., Lee, J., David, R., Benach, J., et al. (2002). Economic inequality, working class power, social capital, and cause specific mortality in wealthy countries. International Journal of Health Services, 32, 629-656.

Murray, M., \& Campbell, C. (2003). Living in a material world: Reflecting on some assumptions of health psychology. Journal of Health Psychology, 8, 231-236.

Murray, M., \& Poland, B. (2006). Health psychology and social action. Journal of Health Psychology, 11, 379-384.

Paxton, W., \& Dixon, M. (2004). The state of the nation: An audit of injustice in the UK. London: Institute for Public Policy Research.

Popay, J. (2000). Social capital: The role of narrative and historical research. Journal of Epidemiology and Community Health, 54, 401.

Popay, J., Bennett, S., Thomas, C., Williams, G., Gatrell, A., \& Bostock, L. (2003). Beyond "beer, fags, egg and chips"? Exploring lay understandings of social inequalities in health. Sociology of Health and Illness, 25, 1-23.

Putnam, R. (2000). Bowling alone: The collapse and revival of American community. New York: Simon \& Schuster.

Putnam, R., Leonardi, R., \& Nanette, R. Y. (1993). Making democracy work: Civic traditions in modern Italy. Princeton, NJ: Princeton University Press.

Rawls, J. (1999). A theory of justice. Cambridge, MA: Belknap.

Repetti, R. L., Seeman, T., \& Taylor, S. E. (1997). Health psychology: What is an unhealthy environment and how does it get under the skin? Annual Review of Psychology, 48, 411-447.

Sachs, J. (2005). The end of poverty: Economic possibilities for our time. London: Penguin.

Shah, A. (2006). Poverty facts and stats. Retrieved July 22, 2006, from http://www.globalissues.org/TradeRelated/Facts.asp

Townsend, P., \& Davidson, N. (1982). Inequalities in health: The Black Report. London: Penguin.

Whitehead. (1995). Tackling inequalities: A review of policy initiatives. In M. Benzeval, K. Judge, \& M. Whitehead (Eds.), Tackling inequalities in health: An agenda for action (pp. 22-52). London: King's Fund.

Wilkinson, R. G. (1996). Unhealthy societies: The afflictions of inequality. London: Routledge.

Williams, G. H. (2003). The determinants of health: Structure, context and agency. Sociology of Health \& Illness, 25, 131-154. 